\title{
Bacterial Adhesion to Hydrocarbons: Role of Asphaltenes and Resins
}

Submitted to:

Colloids and Surfaces B: Biointerfaces

March 29, 2010

CAROLINE WARNE ZOUEKI ${ }^{1+}$, SUBHASIS GHOSHAL ${ }^{2}$, and NATHALIE TUFENKJI ${ }^{*}, 1$

\author{
${ }^{1}$ Department of Chemical Engineering, McGill University, \\ Montreal, Quebec H3A 2B2, Canada
}

${ }^{2}$ Department of Civil Engineering, McGill University, Montreal, Quebec H3A 2K6, Canada

* Corresponding Author. Phone: (514) 398-2999; Fax: (514) 398-6678; E-mail: nathalie.tufenkji@mcgill.ca

+ Current Affiliation. BG Consulting Engineers, 1001 Lausanne, Switzerland 


\begin{abstract}
The influence of asphaltenes and resins on bacterial adhesion to model crude oils was examined using a modified Microbial Adhesion to Hydrocarbons assay. Well-controlled bacterial adhesion experiments were conducted at three solution $\mathrm{pHs}(4,6$ and 7) using Pseudomonas aeruginosa and Pseudomonas putida and four model crude oil systems containing up to four representative hydrocarbon compounds found in crude oils. The model crude oils were designed to independently evaluate the influence of asphaltenes and resins on hydrocarbon surface charge (i.e., electrophoretic mobility) and on bacterial adhesion to the liquid hydrocarbon phase. Asphaltenes and resins were found to make the hydrocarbon droplet surface charge less negative (or more positive) and to generally decrease microbial adhesion to the hydrocarbon. The experimental results were not in qualitative agreement with theoretical predictions of bacteria-hydrocarbon interactions based on the classical or extended Derjaguin-Landau-Verwey-Overbeek interaction energy profiles calculated from measured physicochemical properties of the microorganisms and hydrocarbons. Model calculations considering the role of steric repulsion in bacteria-hydrocarbon interactions suggest that the decreased adhesion behavior in the presence of asphaltenes and resins may be linked to a mechanism of steric hindrance.
\end{abstract}

Keywords: hydrocarbon; bacteria adhesion; asphaltenes; resins; DLVO 


\section{Introduction}

In situ bioremediation is a technology of growing interest for remediation of crude oil contaminated soils and waters. Effective biodegradation depends on various parameters, in particular on the crude oil composition and on the ability of bacteria to adhere to and degrade the hydrocarbon phase. Much research has been performed to understand the physicochemical properties of various crude oil constituents [1]. However, our understanding of how the major components of crude oil can affect bacterial adhesion is still very limited.

Crude oil consists of a complex mixture of aliphatic and aromatic hydrocarbons, as well as asphaltenes and resins. Asphaltenes are high molecular weight compounds containing numerous polar functional groups [1,2] and are often defined as the crude oil fraction which is insoluble in $n$-pentane or $n$-heptane, but soluble in aromatic solvents such as benzene or toluene [3, 4]. Resins are smaller molecules than asphaltenes and soluble in $n$-pentane and $n$-heptane $[1,5]$. Resins are structurally similar to amphiphilic surfactant molecules. In crude oil, they act as peptizing agents keeping asphaltenes in suspension $[1,3,6]$.

Within crude oil-water emulsions, the polar groups of asphaltenes and resins position themselves relative to their affinities for water. Consequently, polar functional groups move to the oil-water interface. Asphaltenes and resins contribute to the surface charge of aqueous oil dispersions [6]. This contribution is partly due to the orientation of the polar functional groups at the oil-water interface [6], and also by ionization of asphaltene and resin acidic and basic functional groups $[3,6]$. In bioremediation applications, the charge at the oil-water interface may give rise to electrical doublelayer interactions between crude oil dispersions and bacteria. 
Favorable interactions between bacteria and oil dispersions may lead to direct adhesion, thereby facilitating hydrocarbon biodegradation [7-12]. The common uptake mechanism for aliphatic hydrocarbon non-aqueous phase liquids (NAPLs) of negligibly low aqueous solubility (e.g., hexadecane), is generally found to be direct uptake associated with bacterial adhesion to oil-water interfaces [13]. The importance of adhesion in the biodegradation process is further demonstrated by the work of Volkering et al. [13], who suggest that inhibition of bacterial adhesion to NAPL-water interfaces, caused by the presence of surfactants, could reduce degradation rates. Hence, the physicochemical properties of the hydrocarbon-water interface may be of particular importance in controlling the rates and extent of biodegradation.

Microbial adhesion to a surface or interface can sometimes be explained by the DerjaguinLandau-Verwey-Overbeek (DLVO) theory of colloidal stability [14]. The DLVO theory quantitatively evaluates the total free energy of interaction between the cell and surface, based on electrical double-layer and van der Waals considerations. Although the DLVO theory was initially developed for inert colloidal particles, it can nonetheless sometimes be used to qualitatively describe microbial adhesion behavior [15], even if the interactions between chemically and structurally complex particles such as bacteria make adhesion predictions difficult.

The Microbial Adhesion to Hydrocarbon (MATH) assay was developed over 25 years ago by Rosenberg et al. [16] to determine microbial cell surface hydrophobicity. The MATH assay involves vortexing a bacterial suspension in the presence of a test liquid hydrocarbon. During the vortexing period, the hydrocarbon phase breaks up into small droplets to which microorganisms adhere, resulting in removal of microorganisms from the bulk aqueous phase. However, Van der Mei et al. 
[17] subsequently found that in addition to surface hydrophobicity, the adhesion of microorganisms to hydrocarbon droplets was $\mathrm{pH}$ dependent. The MATH assay was thus disqualified as a hydrophobicity assay as it was shown to take into account a combination of forces [17-21]. The MATH assay has since become a common method for evaluating bacterial adhesion to a hydrocarbon phase [22, 23]. For example, Abbasnezhad et al. [23] used the MATH assay to show that adhesion to low solubility hydrocarbons was increased by the presence of cationic compounds and long chain alcohols. A modified MATH assay has been proposed that overcomes the recently identified limitations of the classical approach [24].

The objective of this study is to examine the influence of asphaltenes and resins on the surface properties of hydrocarbon droplets and on bacterial adhesion to the hydrocarbon phase. The adhesion of two microorganisms to hydrocarbon droplets is examined over a range of solution $\mathrm{pHs}$ in the presence and absence of asphaltenes and resins using a modified MATH assay [24]. The DLVO theory and a steric model are used to interpret the experimental results, by considering sphere-sphere interactions between bacteria and hydrocarbon droplets during the mixing period of the MATH assay.

\section{Materials and methods}

\subsection{Solution chemistry}

Bacteria and hydrocarbons were prepared in $\mathrm{NaCl}$ (Sigma) solutions at $\mathrm{pH} \mathrm{4,} \mathrm{6,} \mathrm{or} 7$ at a total ionic strength (IS) of $0.2 \mathrm{mM}$. Although this IS is on the lower end of natural freshwater environments, this low IS solution was chosen as a conservative condition where significant droplet and bacterial surface charges would exist. Solution $\mathrm{pH}$ was adjusted using $\mathrm{HCl}$ or $\mathrm{NaOH}$. Analytical reagent grade 
chemicals were used throughout and deionized (DI) (Milli-Q) water was used in washing procedures and solution preparation. All experiments were performed at room temperature $\left(20 \pm 1^{\circ} \mathrm{C}\right)$.

\subsection{Bacteria selection and preparation}

The Gram negative organisms Pseudomonas aeruginosa (P. aeruginosa) ATCC 27853 and Pseudomonas putida (P. putida) F1G4 were used in this study. The species were selected based on their environmental relevance as they are known hydrocarbon degraders and/or naturally present in soils $[10,25]$. The bacteria were plated onto Luria-Bertani (LB) agar plates from frozen stocks kept at $80^{\circ} \mathrm{C}$. Single colonies were used to inoculate cultures in $150 \mathrm{~mL} \mathrm{LB}$ broth at $37^{\circ} \mathrm{C}$ and $200 \mathrm{rpm}$ gyratory shaking. After 18 hrs growth (to late stationary phase), cells were harvested by centrifuging $25 \mathrm{~mL}$ of the culture (Sorvall RC6) for $15 \mathrm{~min}$ at $5860 \mathrm{~g}$ in an SS-34 rotor (Kendro). The growth medium was decanted and the pellet was resuspended in $0.2 \mathrm{mM} \mathrm{NaCl}$. To remove all traces of the growth medium, the cells were centrifuged and resuspended in fresh electrolyte one additional time before use.

\subsection{Hydrocarbon selection and preparation}

Given the complexity of the composition of crude oils, it is of interest to assess adhesion to representative, model hydrocarbon systems. Experiments were performed with four simple model hydrocarbons, prepared as follows: (i) $n$-hexadecane (Sigma, purity $\geq 99 \%$ ); (ii) $n$-hexadecane +0.1 wt $\%$ resins; (iii) $n$-hexadecane $+50 \mathrm{wt} \%$ toluene (Sigma); and (iv) $n$-hexadecane $+50 \mathrm{wt} \%$ toluene + 
$0.1 \mathrm{wt} \%$ asphaltenes. These hydrocarbons are commonly present in crude oil. Furthermore, asphaltenes cannot be dissolved in $n$-hexadecane alone, and thus toluene was added as a co-solvent.

There is a considerable difference in hydrophobicity between toluene and hexadecane: the octanolwater partition coefficient for $n$-hexadecane $\left(\log K_{\mathrm{ow}}=8.25\right)$ is much larger than that of toluene $\left(\log K_{\mathrm{ow}}=2.69\right)[26,27]$. Comparing the results from mixtures (i) and (iii) will reveal the effect of toluene on hydrocarbon droplet surface charge and on bacterial adhesion. Comparison of mixtures (i) and (ii) will reveal the effect of resins, while comparison of mixtures (iii) and (iv) will provide insight on the effect of asphaltenes. Asphaltenes and resins were extracted from Cold Lake crude oil obtained from Shell Canada. Resins were extracted as described in the ASTM D2007 method [28]. Asphaltenes were extracted via $n$-pentane precipitation, as per the ASTM D2007 Appendix X1 method [28] and then dissolved in toluene. Although the selected concentrations of asphaltenes, resins and toluene are not representative of most crude oils, the compositions above ensured that resins and asphaltenes were well dispersed in the hydrocarbon, and did not precipitate out.

\subsection{Characterization of bacteria and hydrocarbon droplets}

Bacterial surface charge was determined from electrophoretic mobility (EPM) measurements (NanoZS, Malvern) conducted on bacterial suspensions prepared in $0.2 \mathrm{mM} \mathrm{NaCl}$ at $\mathrm{pH} 4,6$ and 7. EPM measurements were also performed on silica particles (1.2 $\mu \mathrm{m}$ diameter, Spherotech) at $\mathrm{pH}$ 6, and on hydrocarbon droplets at $\mathrm{pH} 4,6$ and 7. The hydrocarbon droplets were prepared by adding $10 \mu \mathrm{L}$ of the defined hydrocarbon to $1 \mathrm{~mL}$ of the electrolyte in a $10 \times 10 \mathrm{~mm}$ square quartz cuvette (Hellma). The use of a square cuvette was chosen to enhance mixing during the 3 min of vortexing (vortex mixer, 
setting 10, Fisher Scientific). This step was followed by $3 \mathrm{~min}$ of sonication in a bath sonicator (FS60H, Fisher Scientific). Bacteria and hydrocarbon zeta potential values were determined from the EPM measurements using the Smoluchowski equation [29].

Relative cell surface hydrophobicity was evaluated by contact angle measurements (sessile drop technique, OCA 20, Future Digital Scientific Corp.) on bacterial lawns formed on a cellulose acetate membrane filter $(0.45 \mu \mathrm{m}, 47 \mathrm{~mm}$ diameter, Millipore). Bacterial pellets were resuspended in $10 \mathrm{~mL}$ electrolyte and these suspensions were filtered using a vacuum filtration setup with a water aspirator. The bacterial lawn was air-dried before contact angle measurements were conducted. Water (polar), formamide (polar) and diiodomethane (apolar) were used as the three contact angle liquids with known surface tension components. Contact angle measurements were performed on the two bacteria, as well as on a clean quartz surface. For each microorganism tested, at least four measurements were made per contact angle liquid.

Average equivalent spherical radii of the bacteria were determined through analysis of microscope images (IX-71, Olympus) obtained at 30× magnification. The hydrodynamic radii of hydrocarbon droplets were determined by dynamic light scattering (DLS) (Nano-ZS, Malvern). The weighted averages of the hydrodynamic size distributions are used in the interaction energy calculations.

Cell viability during the length of experimentation was confirmed using standard plate counting (CFU) assay. Transmission electron microscopy (TEM) was used to confirm that the integrity of bacterial cells was maintained during the time-scale of the experiments. Samples were prepared by adding a drop of cell suspension $\left(10^{8} \mathrm{CFU} / \mathrm{mL}\right)$ to a drop of $2 \%$ uranyl acetate. A formvar 
coated copper grid (200 mesh) was placed on top of this mixture for $1 \mathrm{~min}$. The grid was then placed on a drop of filter sterilized DI water for $30 \mathrm{sec}$. The grid was blotted dry to remove excess water followed by air drying for $5 \mathrm{~min}$. Measurements were performed on a Philips 410 LS transmission electron microscope (Philips/FEI Corporation, Eindhoven, Holland), fitted with MegaView ll CCD camera (Olympus Soft Imaging Solutions GmbH, Munster, Germany).

\subsection{Cleaning procedure}

All glassware in contact with hydrocarbons was rinsed with acetone, washed with DI water, then acidwashed with $12 \mathrm{M} \mathrm{HCl}$ and flushed repeatedly with DI water. Glassware that had not been in contact with hydrocarbons was simply acid-washed. To ensure that surface characteristics of hydrocarbon droplets or microorganisms were not modified by the presence of undesired surface active agents, the use of detergents was avoided.

\subsection{Measurement of bacterial adhesion to hydrocarbons}

A modified version of the MATH assay was used to evaluate bacterial adhesion to the different hydrocarbon systems [24]. Briefly, the initial concentration of the prepared microbial cell suspensions was determined using a Helber counting chamber (Z30000, Hawksley), viewed under a microscope (IX71, Olympus) operating in phase contrast mode at 10× magnification. In a clean borosilicate glass tube $(16 \times 150 \mathrm{~mm}), 300 \mu \mathrm{L}$ of the model crude oil was added to $5 \mathrm{~mL}$ of the bacterial suspension. The tube was vortexed for 2 min (vortex mixer, setting 8, Fisher), and set aside for 15 min to allow for phase separation. A sample of the bacterial suspension was retrieved with a clean Pasteur pipet, while taking great care to avoid uptake of the hydrocarbon layer into the pipet. This bacterial sample 
was retrieved at a time point where the hydrocarbon droplet size was determined to be stable. Ten $\mu \mathrm{L}$ of this sample was transferred to the Helber counting chamber and the cell concentration was determined. The fraction partitioned to the hydrocarbon phase was calculated as $\left(F P=1-C_{f} / C_{\mathrm{o}}\right)$, where $C_{\mathrm{o}}$ is the concentration of the bacterial suspension before mixing and $C_{\mathrm{f}}$ is the concentration after mixing. The modified MATH assays were performed for $P$. putida and $P$. aeruginosa (at $\mathrm{pH} 4$,

6 and 7), as well as for silica particles (at $\mathrm{pH} 6$ ), with an initial concentration $C_{\mathrm{o}}$ of approximately $5 \times 10^{7}$ particles $/ \mathrm{mL}$ or cells $/ \mathrm{mL}$. The $\mathrm{pH}$ of the suspensions was stable over the timescale of the MATH assays for each $\mathrm{pH}$ examined.

\section{Results and discussion}

\subsection{Characterization of bacteria}

EPM measurements obtained at $\mathrm{pH} \mathrm{4,6}$ and 7 for both microorganisms are shown in Figure 1. The selected bacteria are negatively charged at the three $\mathrm{pH}$ values examined. The EPM of the two Pseudomonas strains becomes less negative at the lowest $\mathrm{pH}$ and their isoelectric points seem to be less than 4 .

[FIGURE_1_HERE]

Contact angle measurements on bacterial lawns are commonly used to characterize the relative hydrophobicity of cell surfaces $[14,30]$. Measurements performed on lawns of the two microorganisms prepared in $0.2 \mathrm{mM} \mathrm{NaCl}$ at $\mathrm{pH} 6$ are reported in Table 1. P. aeruginosa is slightly hydrophobic, with a water contact angle of $\sim 95^{\circ}$, whereas $P$. putida is hydrophilic, with a water contact angle of $-35^{\circ}$. Contact angle results are used for the calculation of the apolar surface tension value 
$\gamma^{L W}$ and the polar surface tension values $\gamma^{+}$and $\gamma^{-}$(Table 1) which are then used to evaluate the Hamaker constant for the bacteria-hydrocarbon droplet interaction [30].

The equivalent spherical diameters $P$. putida and $P$. aeruginosa were determined through analysis of microscope images and range from $0.7 \mu \mathrm{m}$ to about $1 \mu \mathrm{m}$. Results are presented in Table 1 and are used along with determined zeta potentials in interaction energy profile calculations. TEM analysis of bacterial cells collected before and after MATH assays revealed no observable damage to cell walls. Cells were observed to be similar in shape and size and exhibited flagella, both before and after exposure to hydrocarbons.

\section{[TABLE_1_HERE]}

\subsection{Characterization of hydrocarbon droplets}

EPM measurements were performed on (i) hexadecane (H), (ii) hexadecane/resins (HR), (iii) hexadecane/toluene (HT) and (iv) hexadecane/toluene/asphaltene (HTA) droplets suspended in 0.2 $\mathrm{mM} \mathrm{NaCl}$ at $\mathrm{pH} \mathrm{4,6}$ and 7. Data shown in Figure 2a allow us to evaluate the effect of resins on hydrocarbon droplet EPM. Results in Figure 2a generally show that the presence of resins makes the charge at the oil-water interface less negative; however the difference was statistically significant only at $\mathrm{pH} 6$ (Exact Mann-Whitney $\mathrm{U}$ test, $\alpha=0.1$ ). Experiments conducted to evaluate the influence of asphaltenes on hydrocarbon charge (Figure 2b) demonstrate that the EPM of hydrocarbon droplets is significantly less negative in the presence of asphaltenes at $\mathrm{pH}$ 4, 6 and 7 (Exact Mann-Whitney $\mathrm{U}$ 
test, $\alpha=0.1$ ). The data presented in Figure 2 suggest that both asphaltenes and resins make the surface charge of hydrocarbon droplets less negative (or more positive) for any of the $\mathrm{pH}$ values examined.

[FIGURE_2_HERE]

Parra-Barraza et al. [3] found that $n$-heptane insoluble asphaltenes extracted from bitumen of high resin/asphaltene ratio carry a negative charge at $\mathrm{pH}$ values greater than $\mathrm{pH} 5$, and a positive charge at $\mathrm{pH}$ values below $\mathrm{pH} 5$. Asphaltenes contain $\mathrm{pH}$-dependent ionizable functional groups. A negative charge could arise by dissociation of acidic functional groups such as carboxylic acid, and a positive charge from protonation of basic functional groups [3]. The positive shift in charge observed in Figure $2 \mathrm{~b}$ in the presence of asphaltenes was likely caused by protonation of basic nitrogencontaining functional groups such as pyridine [3].

EPMs measured for $\mathrm{H}$ and $\mathrm{HT}$ droplets in Figure 2 were negative and comparable to results obtained by other researchers [18, 31-33]. Busscher et al. [18] and Marinova et al. [31] attributed this negative charge to the specific adsorption of hydroxyl ions from dissociation of water molecules. The negative charge may also be contributed by adsorption of anions such as bicarbonate or carbonate ions $[18,32]$, or chloride ions from the electrolyte components [33]. Unlike Busscher et al. [18] who observed a more negative charge for aliphatic hydrocarbon droplets in comparison to aromatic hydrocarbon droplets, results in this study showed no significant difference when samples were prepared with or without the aromatic compound toluene at $\mathrm{pH}$ 4, 6 and 7 (Exact Mann-Whitney $\mathrm{U}$ test, $\alpha=0.1$ ) (Figure 2). 
The average hydrodynamic diameters of hydrocarbon droplets were determined for all hydrocarbon systems at $\mathrm{pH}$ 4, 6 and 7. Negligible variation in diameter was found between $\mathrm{pH}$ values (Table 1). The average diameters of $\mathrm{H}, \mathrm{HR}, \mathrm{HT}$ and HTA droplets ranged between 1.3 and $2.3 \mu \mathrm{m}$ (averaged for all $\mathrm{pH}$ values).

\subsection{Bacterial adhesion to hydrocarbons}

A modified MATH assay [24] was used to evaluate adhesion of $P$. putida and $P$. aeruginosa to the four model hydrocarbon systems over a range of $\mathrm{pH}$ values. These data (Figure 3 ) are used to provide insight on the effect of $\mathrm{pH}$ and the presence of asphaltenes and resins on microbial adhesion behavior.

[FIGURE_3_HERE]

The total interaction energy upon approach of a bacterial cell to a hydrocarbon droplet was evaluated within the context of the Derjaguin-Landau-Verwey-Overbeek (DLVO) theory which is commonly used to explain the physicochemical processes that govern the initial phase of bacterial adhesion $[34,35]$. The electrical double layer interaction energy was estimated using a linear superposition approximation presented by Bell et al. [36] and the retarded Liftshitz-van der Waals interaction energy for the interaction of two spherical particles was evaluated using the expression of Gregory [37]. It should be noted that the shape of the interaction energy profiles based on the classical DLVO theory (Figures 4 and 5) are very similar to the profiles predicted based on the XDLVO theory [22] that also considers the contribution of acid-base interactions (XDLVO profiles not shown).

[FIGURE_4_HERE]

[FIGURE_5_HERE] 


\subsubsection{Effect of solution $p H$ on bacterial adhesion}

DLVO calculations resulted in a minimal height of the predicted interaction energy barrier for both Pseudomonas species at $\mathrm{pH} 4$ versus the two higher $\mathrm{pH}$ values examined (Figure 4). Accordingly, higher partitioning fractions are observed for these organisms at $\mathrm{pH} 4$ and lesser adhesion at $\mathrm{pH} 6$ and 7 (Figure 3), where repulsive forces are strong and the energy barriers are non-negligible. These trends in adhesion at different $\mathrm{pH}$ values for the two Pseudomonas species are in qualitative agreement with the DLVO theory. The addition of toluene generally resulted in greater adhesion values for both microorganisms, as shown by the partitioning fractions in Figure 3. However, the observed increased adhesion in the presence of toluene is generally not in qualitative agreement with predictions based on DLVO theory when considering attachment in the primary energy minimum (Figures 4 and 5). Specifically, the predicted heights of the energy barriers for the interaction of each organism with a droplet containing toluene (i.e., HT) (Figure 5) are generally greater than those calculated for the interaction with a droplet containing $n$-hexadecane alone (i.e., H) (Figure 4).

\subsubsection{Effect of asphaltenes and resins on bacterial adhesion}

The effect of resins on bacterial adhesion can be evaluated by examining the partitioning fractions in Figure 3 for the $\mathrm{H}$ and $\mathrm{HR}$ systems. Both microorganisms demonstrate an increase in adhesion to $\mathrm{HR}$ in comparison to $\mathrm{H}$ at $\mathrm{pH} 4$. However, at $\mathrm{pH} \mathrm{6,} \mathrm{the} \mathrm{presence} \mathrm{of} \mathrm{resins} \mathrm{resulted} \mathrm{in} \mathrm{decreased}$ adhesion for the two organisms considered. A decrease in adhesion was also observed at $\mathrm{pH} 7$ for $P$. aeruginosa. 
Fractions partitioned to HT and HTA in Figure 3 can be compared in an effort to understand the effect of asphaltenes on adhesion of both Pseudomonas species. In the presence of asphaltenes, adhesion decreased for $P$. aeruginos $a$ at all $\mathrm{pH}$ values, and for $P$. putida at $\mathrm{pH} 6$ and $\mathrm{pH} 7$. For instance, asphaltenes significantly decreased adhesion for $P$. putida (28\% cells partitioned to HT and only $7 \%$ to HTA) and for $P$. aeruginosa (59\% cells partitioned to HT and only $40 \%$ to HTA) at $\mathrm{pH} 6$ (Figure 3).

The decrease in adhesion observed in the presence of asphaltenes and resins cannot be explained from a purely electrostatics point of view. Figure 2 reveals that the surface charges of HR and HTA droplets are more positive than $\mathrm{H}$ and $\mathrm{HT}$ droplets, respectively. A more positive hydrocarbon droplet surface charge is expected to result in a decrease in electrostatic repulsion and therefore an increase in bacterial adhesion (based on DLVO theory). When total DLVO interaction energy profiles are considered (Figure 5), the presence of asphaltenes theoretically results in attractive interactions at $\mathrm{pH} 4$ and 6, and in a lower repulsive energy barrier between cells and hydrocarbon droplets at $\mathrm{pH} 7$, thereby facilitating adhesion. Yet, the general observation in the experiments (Figure 3) is that asphaltenes cause the opposite behavior. In effect, the data in Figure 3 show that the presence of asphaltenes in hydrocarbons generally reduces bacterial adhesion, contrarily to what could be expected based on DVLO theory.

\subsubsection{Possible role of steric interactions}

The measurements of bacterial adhesion to the four model hydrocarbon systems (Figure 3) do not always follow the predictions based on DLVO theory. Bacteria possess surface macromolecules 
including lipopolysaccharides, proteins, and complex lipids extending from the cell surface which may inhibit adhesion through steric interactions [14, 38-41]. Asphaltenes and resins, which are surface active, extend from the hydrocarbon droplet interface [42]. Such polymers extending from the cell surfaces and from HR and HTA droplets may give rise to steric repulsion due to compression and interpenetration of polymers. Steric repulsion could explain the observed decrease in adhesion to HR and HTA that could not be explained by the DLVO calculations.

To estimate the magnitude of interaction between bacteria and asphaltene-containing hydrocarbon droplets, repulsive steric interaction energies were calculated using the Alexander-deGennes equation [43]. In this approach, the Pseudomonas species and HTA droplets were approximated as two polymer brush systems, and it was assumed that the polymers are completely soluble or miscible in the electrolyte. Other researchers [44-46] determined the surface polymer lengths and grafting densities needed for these steric calculations. Sztukowski et al. [44] determined the values for $n$-heptane insoluble asphaltenes extracted from Athabasca oil sands bitumen. These asphaltenes were found to extend 2 to $9 \mathrm{~nm}$ from the oil-water interface, with an average molecular area of $1.55 \mathrm{~nm}^{2}$, which is equivalent to a surface coverage of approximately 50 self-associated asphaltene molecules per $\mathrm{nm}^{2}$. Arora [45] has shown that $P$. putida KT2442 has a polymer grafting density of $2.48 \times 10^{-3}$ polymers $/ \mathrm{nm}^{2}$ with an average length of $728 \mathrm{~nm}$. According to Emerson and Camesano [46], P. aeruginosa ATCC 10145 has two polymer layers, each with a different grafting density and brush length. The shorter polymer layer of $24.0 \mathrm{~nm}$ has $7.5 \times 10^{-2}$ polymers $/ \mathrm{nm}^{2}$, and the longer polymer layer has $2.5 \times 10^{-2}$ polymers $/ \mathrm{nm}^{2}$ with a brush length of $92.6 \mathrm{~nm}$. These values were used to calculate the total interaction energy (electrical double layer+Liftshitz-van der Waals+steric 
interaction energies) between HTA droplets and Pseudomonas species. Highly repulsive interaction energies resulted from the calculations at all separation distances (energy profiles not shown). Repulsive energy barriers were estimated to be on the order of $10^{6} \mathrm{kT}$ per cell for $P$. putida, and $\sim 10^{4}$ to $10^{5} k T$ per $P$. aeruginosa cell at $\mathrm{pH} 6$. The total interaction energy values are completely dominated by the highly repulsive steric interaction. Although this analysis is a rough estimation of steric interaction energies, it implies a definite hindrance to adhesion in the presence of asphaltenes.

To further evaluate whether polymers extending from microbial cells may have contributed to the decrease in adhesion to HR and HTA droplets, the adhesion assay was performed with model control particles. Silica particles were chosen as they are non-biological, relatively smooth and expected to demonstrate comparable adhesion behavior as bacteria, minus the effect of steric repulsion by interpenetration of polymers. The experimental adhesion results for silica particles at $\mathrm{pH} 6$ show a significant increase in adhesion in the presence of asphaltenes and resins (Figure 6). This result reflects well the DLVO interaction energy profiles in Figure 6c based on EPM measurements for silica (3.52 $\pm 0.03 \mu \mathrm{mcm} / \mathrm{Vs})$. The calculated energy profile predicts an attractive interaction between silica and the asphaltene-containing hydrocarbon (Figure 6c). Silica particles and microorganisms exhibit very different adhesion behaviors (Figures 6 and 3) despite their similar predicted interaction energy profiles (Figures 4 and 6c). This difference may be an indication that, unlike silica particles which are smooth, microorganisms may indeed be repelled by HR and HTA droplets through steric stabilization caused by polymer interpenetration.

[FIGURE_6_HERE] 
The increased adhesion of silica particles to the HR and HTA hydrocarbons could also be explained by attractive steric interactions. Polymers which have an affinity to a surface with free binding sites generally undergo a bridging mechanism, giving rise to an attractive bridging force [47]. Asphaltenes and resins are known to have a strong affinity to mineral surfaces, such as silica $[4,48]$. Asphaltene and resin molecules extending from the hydrocarbon droplets may have been attracted to the smooth silica particles. This would give rise to an attractive bridging force, thereby increasing adhesion in the presence of asphaltenes and resins.

Steric effects possibly play a role in the interaction between the smooth $\mathrm{H}$ and HT droplets and the biopolymers expressed by the Pseudomonas species. An attractive bridging force is expected only if the polymers extending from the cells are compatible with $\mathrm{H}$ and HT surfaces. Minimal adhesion to $\mathrm{H}$ and $\mathrm{HT}$ was observed for both Pseudomonas species (Figure 3), implying a possible incompatibility for the biopolymers with the hydrocarbons. Therefore, it is likely that Pseudomonas cells experienced steric repulsion due to compression of biopolymers upon approach of the smooth $\mathrm{H}$ and HT hydrocarbon droplets.

\section{Conclusions}

DLVO (and XDLVO) interaction energies were found to inadequately predict the interactions between microorganisms and model crude oils, in the presence of asphaltenes and resins. Steric interactions may play an important role in the observed discrepancies between the DLVO (and XDLVO) predictions and observed bacterial adhesion behavior. It should be noted that bacteriahydrocarbon interactions are very complex and the simplified model calculations presented here do not take into account all possible synergistic molecular level interactions. Nevertheless, the 
experimental results in this study contribute to our understanding of bacterial adhesion to hydrocarbons.

Asphaltenes and resins were shown to make the hydrocarbon droplet surface charge more positive, and to generally decrease microbial adhesion. This result has not previously been shown in other studies and may have significant environmental implications. Furthermore, adhesion was found to be more favorable in the presence of toluene, therefore such aromatic hydrocarbons may increase adhesion and direct uptake of hydrocarbons. NAPLs containing asphaltene and resin fractions are likely to be harder to degrade by microorganisms that depend on adhesion to hydrocarbon phases for hydrocarbon uptake. The surface properties of specific bacteria, as well as the specific asphaltenes and resins present in a hydrocarbon phase will however determine the extent of adhesion. Ongoing studies in our laboratory are aimed at evaluating the combined effects of surface active agents (e.g., resins and asphaltenes) at various doses representative of common crude oils. 


\section{Acknowledgements}

This research was supported by NSERC Discovery Grants awarded to N.T. and S.G., the McGill India Strategic Research Initiative (MISRI), a Eugenie Ulmer Lamothe award to C.W.Z., and the CRC and CFI Programs. The authors acknowledge A. Bhakta (McGill) for conducting TEM analysis, S. Mukherji (IIT Bombay) for helpful discussions, M. Assanta (AAFC) for providing ATCC 27853 and ATCC 700732, P. Lau (NRC) for providing P. putida F1G4 and Shell Canada for supplying Cold Lake crude oil. 


\section{References}

[1] O.C. Mullins, E.Y. Sheu, A. Hammami and A.G. Marshall, Asphaltenes, Heavy Oils, and Petroleomics. Springer: New York, 2007; p 669.

[2]J. Zheng, S.H. Behrens, M. Borkovec and S.E. Powers, Environmental Science and Technology 35 (2001) 2207-2213.

[3]H. Parra-Barraza, D. Hernandez-Montiel, J. Lizardi, J. Hernandez, R. Herrera Urbina and M.A. Valdez, Fuel 82 (2003) 869-874.

[4]T. Abraham, D. Christendat, K. Karan, Z. Xu and J. Masliyah, Industrial \& Engineering Chemistry Research 41 (2002) 2170-2177.

[5]S. Ghoshal, M. Alshafie and C. Pasion, Environmental Science and Technology 38 (2004) 2102-2110.

[6]A. Jada and M. Salou, Journal of Petroleum Science and Engineering 33 (2002) 185-193.

[7]R.K. Hommel, Biodegradation 1 (1990) 107-119.

[8]F. Baldi, N. Ivosevic, A. Minacci, M. Pepi, R. Fani, V. Svetlicic and V. Zutic, Applied and Environmental Microbiology 65 (1999) 2041-2048.

[9]M. Rosenberg and E. Rosenberg, Journal of Bacteriology 148 (1981) 51-57.

[10]R.S. Norman, R. Frontera-Suau and P.J. Morris, Applied and Environmental Microbiology 68 (2002) 5096-5103.

[11]J.D. Van Hamme and O.P. Ward, Journal of Applied and Environmental Microbiology 67 (2001) 48744879.

[12]L.G. Whyte, S.J. Slagman, F. Pietrantonio, L. Bourbonniere, S.F. Koval, J.R. Lawrence, W.E. Inniss and C.W. Greer, Applied and Environmental Microbiology 65 (1999) 2961-2968.

[13]F. Volkering, A.M. Breure and W.H. Rulkens, Biodegradation 8 (1998) 401-417.

[14]M. Hermansson, Colloids and Surfaces B: Biointerfaces 14 (1999) 105-119.

[15]M.C.M. van Loosdrecht, J. Lyklema, W. Norde and A.J.B. Zehnder, Microbial Ecology 17 (1989) 1-15.

[16]M. Rosenberg, D. Gutnick and E. Rosenberg, FEMS Microbiology Letters 9 (1980) 29-33.

[17]H.C. van der Mei, B. van de Belt-Gritter and H.J. Busscher, Colloids and Surfaces B: Biointerfaces 5 (1995) 117.

[18]H.J. Busscher, B. van de Belt-Gritter and H.C. van der Mei, Colloids and Surfaces B: Biointerfaces 5 (1995) 111.

[19]G.I. Geertsema-Doornbusch, H.C. van der Mei and H.J. Busscher, Journal of Microbiological Methods 18 (1993) 61-68.

[20]H.C. van der Mei, J. De Vries and H.J. Busscher, Applied and Environmental Microbiology 59 (1993) 4305-4312.

[21]H.C. van der Mei, A.H. Weerkamp and H.J. Busscher, Journal of Microbiological Methods 6 (1987) 277-287.

[22]R. Bos, H.C. van der Mei and H.J. Busscher, FEMS Microbiology Reviews 23 (1999) 179-230.

[23]H. Abbasnezhad, M.R. Gray and J.M. Foght, Colloids and Surfaces B: Biointerfaces 62 (2008) 36-41.

[24]C. Warne Zoueki, N. Tufenkji and S. Ghoshal, Journal of Colloid and Interface Science 344 (2010) 492496.

[25]G.J. Zylstra and D.T. Gibson, Journal of Biological Chemistry 264 (1989) 14940-14946.

[26]M. Coates, D.W. Connell and D.M. Barron, Environmental Science and Technology 19 (1985) 628-

632.

[27] R.P. Schwarzenbach, M. Gschwend and D.M. Imboden, Environmental Organic Chemistry. John Wiley \& Sons: New York, 1992; p 681. 
[28] Annual Book of ASTM Standards. D 2007. 1998.

[29]R.J. Hunter, Foundations of Colloid Science. Oxford University Press: New York, 2001; p

806.

[30] C.J. van Oss, Interfacial Forces in Aqueous Media. Marcel Dekker: New York, 1994; p 440.

[31]K.G. Marinova, R.G. Alargova, N.D. Denkov, O.D. Velev, D.N. Petsev, I.B. Ivanov and R.P. Borwankar, Langmuir 12 (1996) 2045-2051.

[32]K.B. Medrzycka, Colloid \& Polymer Science 269 (1991) 85-90.

[33]A. Avranas, G. Stalidis and G. Ritzoulis, Colloid and Polymer Science 266 (1988) 937-940.

[34]B.V. Derjaguin and L.D. Landau, Acta Physicochim. URSS 14 (1941) 733-762.

[35] E.J.W. Verwey and J.T.G. Overbeek, 1948. Theory of the Stability of Lyophobic Colloids, Elsevier, Amsterdam.

[36]G.M. Bell, S. Levine and L.N. McCartney, Journal of Colloid and Interface Science 33 (1970) 335-359.

[37]J. Gregory, Journal of Colloid and Interface Science 83 (1981) 138-145.

[38]A. Atabek and T.A. Camesano, Journal of Bacteriology 189 (2007) 8503-8509.

[39]H.H.M. Rijnaarts, W. Norde, E.J. Bouwer, J. Lyklema and A.J.B. Zehnder, Colloids and Surfaces B:

Biointerfaces 4 (1995) 5-22.

[40]C.H. Bell, B.S. Arora and T.A. Camesano, Environmental Engineering Science 22 (2005) 629-641.

[41]T.D. Cloud and R. Rajagopalan, Journal of Colloid and Interface Science 266 (2003) 304-313.

[42]A.P. Sullivan and P.K. Kilpatrick, Ind. Eng. Chem. Res. 41 (2002) 3389-3404.

[43]P.G. de Gennes, Advances in Colloid and Interface Science 27 (1987) 189-209.

[44]D.M. Sztukowski, M. Jafari, H. Alboudwarej and H.W. Yarranton, Journal of Colloid and Interface Science 265 (2003) 179-186.

[45] Arora, B.S. Masters Thesis, Worcester Polytechnic Institute, Worcester, MA, 2003.

[46]R.J. Emerson and T.A. Camesano, Applied and Environmental Microbiology 70 (2004) 6012-6022.

[47]J.N. Israelachvili, Intermolecular and Surface Forces, 2nd ed. Academic Press: London, 1992; p 450.

[48]W.H. Anckner and S.E. Powers, Non-Aqueous Phase Liquids (NAPLs) in Subsurface Environment: Assessment and Remediation (1996).

[49] C.J. van Oss, Journal of Colloids and Surfaces A: Physicochemical and Engineering Aspects 78 (1993) 1-49.

[50] S. Poteau and J.F. Argillier, Energy \& Fuels 19 (2005) 1337-1341.

[51] K. Xie and K. Karan, Energy \& Fuels 19 (2005) 1252-1260. 


\section{Table 1}

Summary of bacteria and hydrocarbon properties

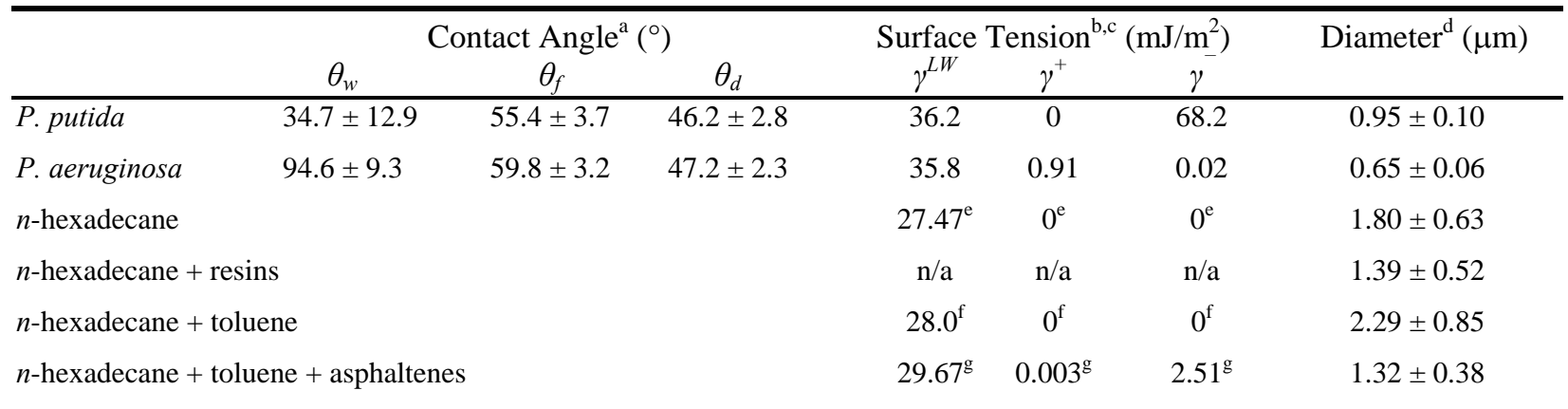

a Contact angles of the bacterial films with water $\left(\theta_{w}\right)$, formamide $\left(\theta_{f}\right)$ and diiodomethane $\left(\theta_{d}\right)$ (values are presented as means $\pm \mathrm{SD}$, sample size $n=4$ ).

${ }^{\mathrm{b}}$ Bacteria surface tension values for apolar Liftshitz-van der Waals $\left(\gamma^{\mathrm{LW}}\right)$ and polar acid $\left(\gamma^{+}\right)$and base $(\gamma-)$ components determined by means of contact angle measurements [49].

${ }^{\mathrm{c}}$ The effect of $\mathrm{pH}$ on surface tension is ignored [50].

${ }^{\mathrm{d}}$ Equivalent spherical diameter of microorganisms determined by microscopy, and hydrodynamic diameter of hydrocarbon droplets determined by DLS (values are averaged over all three $\mathrm{pHs}$ ).

${ }^{\text {e }}$ From ref. [30]

${ }^{\mathrm{f}}$ Average of surface tension of hexadecane and toluene (values from ref.[30])

${ }^{g}$ From ref. [51] 
FIGURE 1. Electrophoretic mobility of bacteria at $\mathrm{pH} 4,6$ and 7 . Cells were suspended in 0.2 $\mathrm{mM} \mathrm{NaCl}$ for all measurements. Error bars denote \pm 1 standard deviation (SD), with sample size $n=5$.

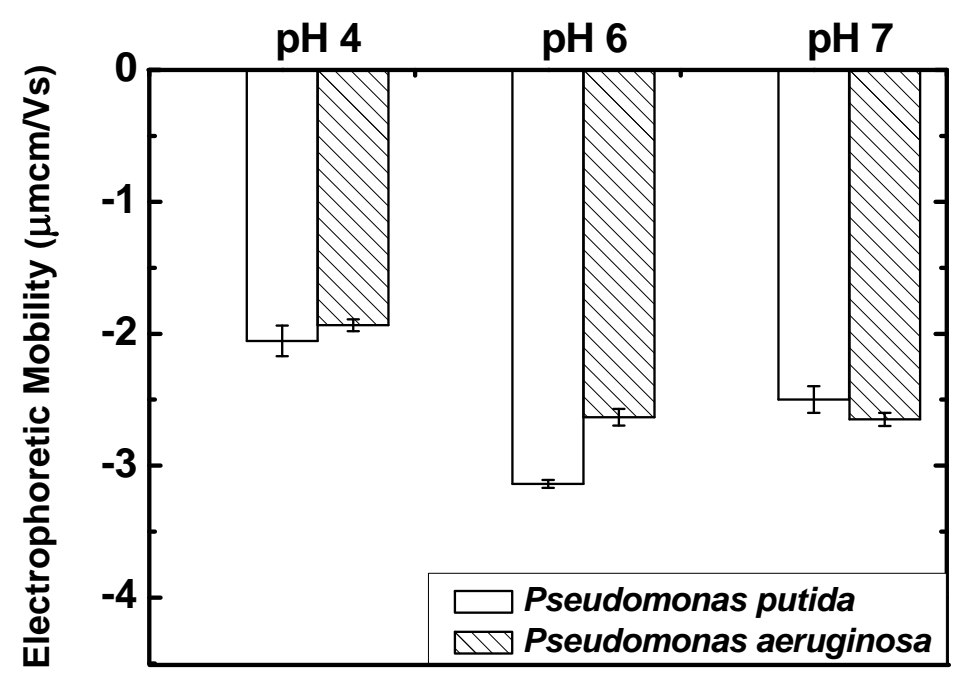

Warne Zoueki et al. FIGURE 1 
FIGURE 2. (a) Electrophoretic mobility of hexadecane $(\mathrm{H})$ droplets and hexadecane/resins (HR) droplets, and (b) electrophoretic mobility of hexadecane/toluene (HT) droplets and hexadecane/toluene/asphaltenes (HTA) droplets. Hydrocarbon droplets were prepared in 0.2 $\mathrm{mM} \mathrm{NaCl}$ at $\mathrm{pH}$ 4, 6 and 7. Error bars denote $\pm 1 \mathrm{SD} .{ }^{*}$ Significantly larger, with $\alpha=0.1$ (Exact Mann-Whitney $\mathrm{U}$ test, $n=5$ ).

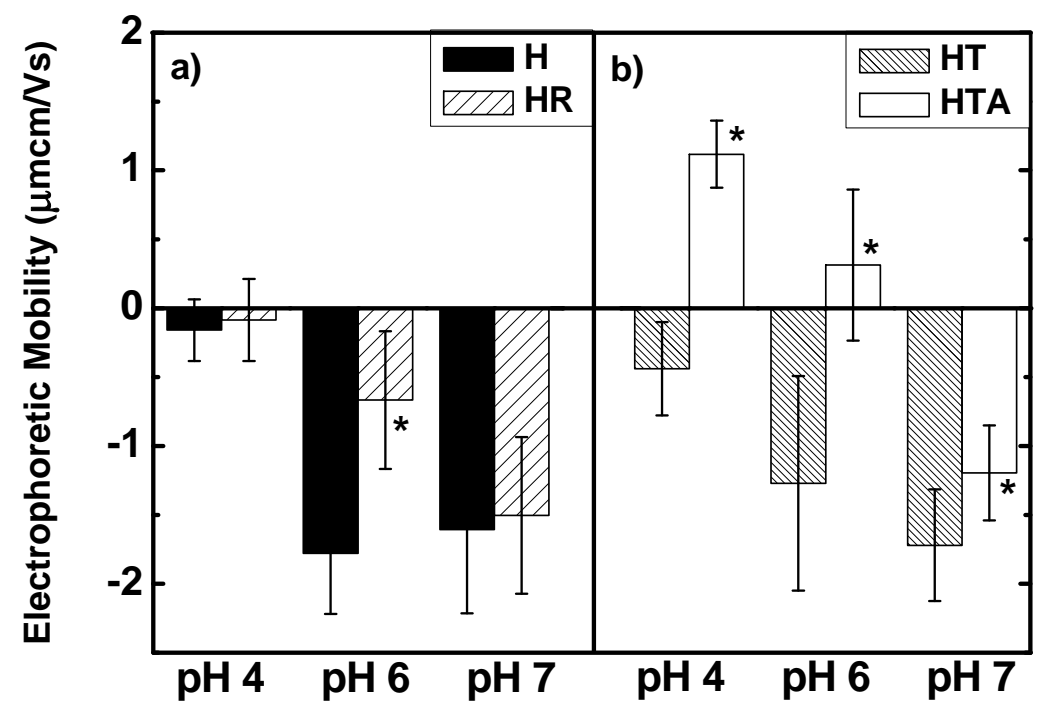

\section{Warne Zoueki et al.} FIGURE 2 
FIGURE 3. Fraction of (a) $P$. putida and (b) $P$. aeruginosa cells partitioned to (i) the hexadecane phase $(\mathrm{H})$ or to the hexadecane/resins phase (HR), and (ii) to the hexadecane/toluene phase (HT) or to the hexadecane/toluene/asphaltene phase (HTA). Cells were suspended in 0.2 $\mathrm{mM} \mathrm{NaCl}$ at $\mathrm{pH}$ 4, 6 and 7. Error bars denote $\pm 1 \mathrm{SD}$. *Significantly larger, with $\alpha=0.1$ (Exact Mann-Whitney U test, $n=5$ ).

a) P. putida

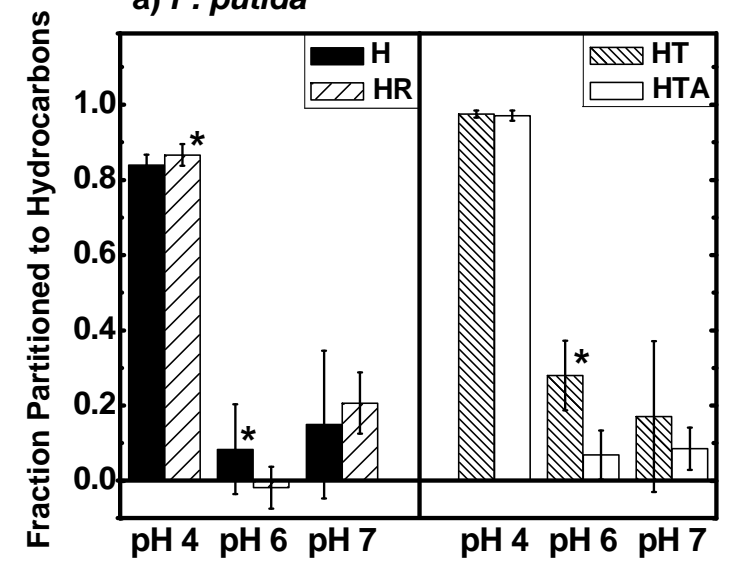

b) $P$. aeruginosa

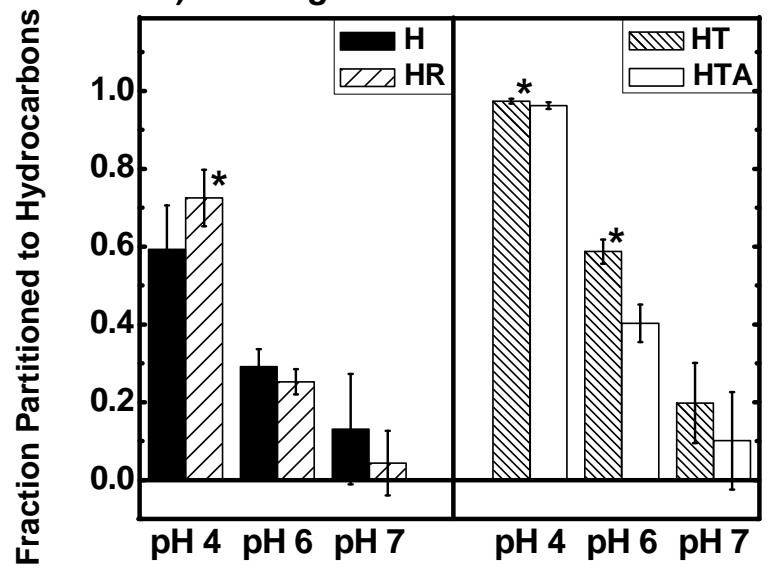

Warne Zoueki et al. FIGURE 3 
FIGURE 4. Total interaction energy as a function of separation distance calculated using DLVO model for (a) Pseudomonas putida and (b) Pseudomonas aeruginosa cells interacting with $n$-hexadecane droplets at $\mathrm{pH} 4,6$ and 7 .

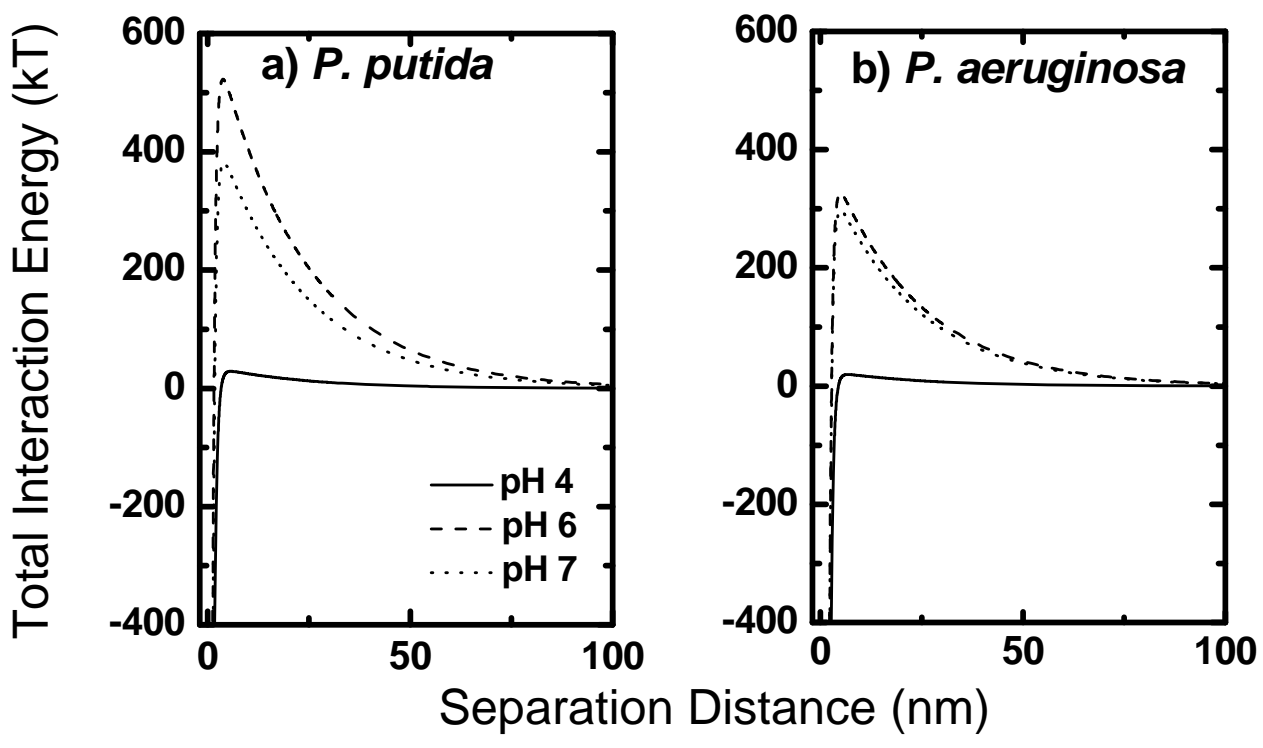

Warne Zoueki et al. FIGURE 4 
FIGURE 5. Total interaction energy as a function of separation distance calculated using DLVO model for (a)-(c) P. aeruginosa or (d)-(f) P. putida interacting with HT and HTA droplets.
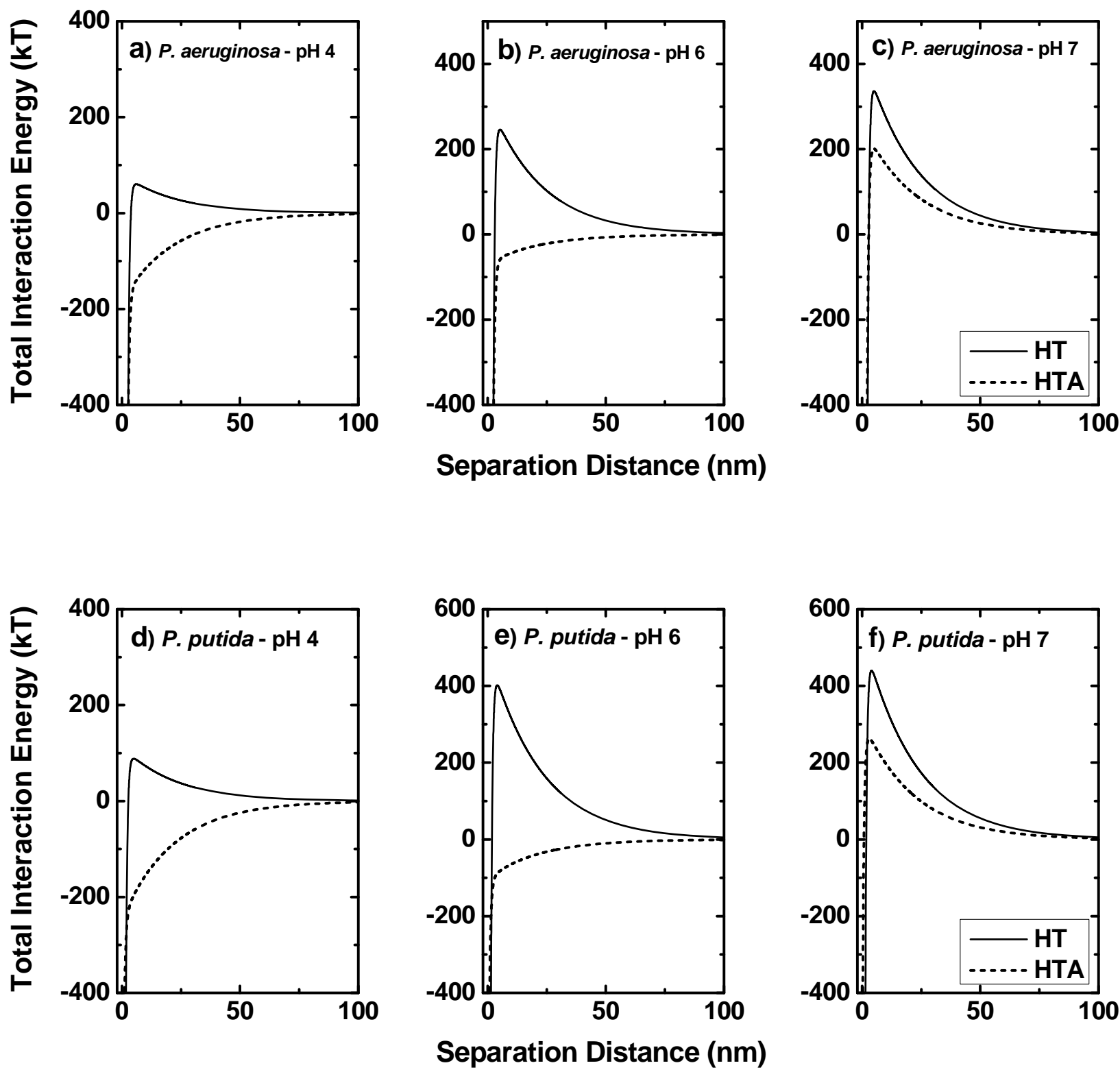

Warne Zoueki et al. FIGURE 5 
FIGURE 6. (a) Fraction of silica particles partitioned to the hexadecane phase $(H)$ or to the hexadecane/resins phase (HR), and (b) to the hexadecane/toluene phase (HT) or to the hexadecane/toluene/asphaltenes phase (HTA). Silica particles were suspended in $0.2 \mathrm{mM} \mathrm{NaCl}$ at $\mathrm{pH}$ 6. Error bars denote $\pm 1 \mathrm{SD}$. *Significantly larger, with $\alpha=0.1$ (Exact Mann-Whitney U test, $n=5$ ). (c) Total interaction energy with distance for silica particles interacting with H, HT and HTA droplets at pH 6 calculated using DLVO model.
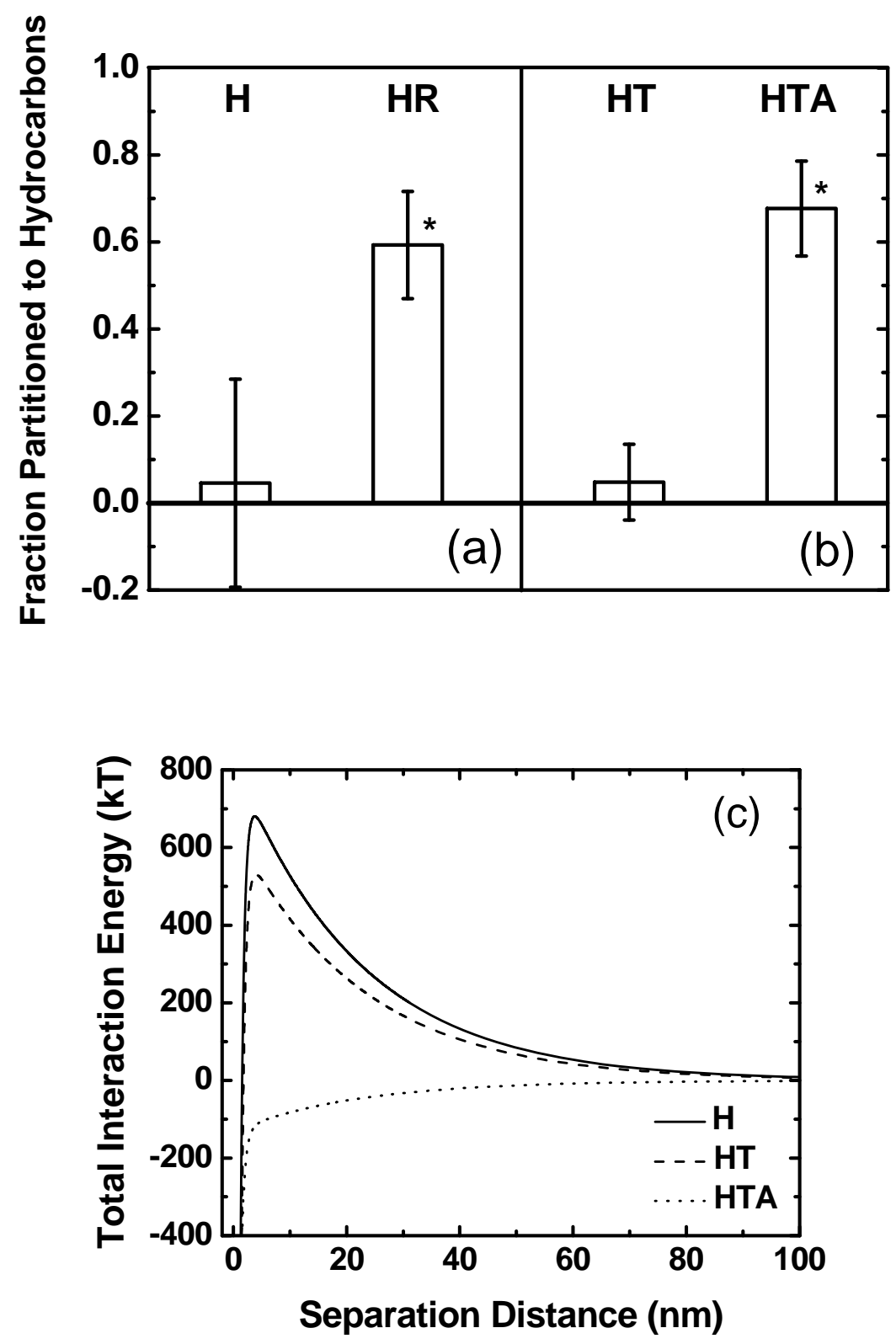